\title{
BMJ Open Association of sudden sensorineural hearing loss with asthma: a longitudinal follow-up study using a national sample cohort
}

\author{
Hyo Geun Choi (D) , ${ }^{1}$ Chanyang Min, ${ }^{2}$ Chang Ho Lee, ${ }^{3}$ So Young Kim (D) ${ }^{4,4}$
}

To cite: Choi HG, Min C, Lee CH, et al. Association of sudden sensorineural hearing loss with asthma: a longitudinal follow-up study using a national sample cohort. BMJ Open 2022;12:e047966. doi:10.1136/ bmjopen-2020-047966

- Prepublication history for this paper is available online. To view these files, please visit the journal online (http://dx.doi. org/10.1136/bmjopen-2020047966).

Received 15 December 2020 Accepted 22 December 2021

Check for updates

(c) Author(s) (or their employer(s)) 2022. Re-use permitted under CC BY-NC. No commercial re-use. See rights and permissions. Published by BMJ.

${ }^{1}$ Department of

Otorhinolaryngology-Head \& Neck Surgery, Hallym University, Anyang-si, Republic of Korea ${ }^{2}$ Hallym University Sacred Heart Hospital, Anyang, Gyeonggi-do, Republic of Korea

${ }^{3}$ Department of

Otorhinolaryngology-Head \&

Neck Surgery, CHA University, Pocheon, Republic of Korea

${ }^{4}$ Department of

Otorhinolaryngology-Head \&

Neck Surgery, Hallym University College of Medicine, Chuncheon, Republic of Korea

Correspondence to Professor So Young Kim; sossi81@hanmail.net

\section{ABSTRACT}

Objective To investigate the risk of sudden sensorineural hearing loss (SSNHL) in asthma patients.

Design A longitudinal follow-up study using a retrospective cohort

Setting The 2002-2013 Korean National Health Insurance Service-Health Screening Cohort

Participants and interventions The $\geq 40$ years old Korean population were enrolled. The asthma patients were 1:1 matched with the control group for age, sex, income and region of residence.

Main outcome measure The occurrence of SSNHL was followed in both asthma and control groups. The stratified Cox proportional hazard model was used. Age, sex, income and region of residence were stratified, and Charlson Comorbidity Index scores, obesity, smoking, alcohol consumption and atopic dermatitis histories were adjusted. Subgroup analysis was performed according to age, sex, obesity, smoking and alcohol consumption.

Results The results showed that $1.0 \%$ (877/90 564) of the asthma group and $0.8 \%(706 / 90,564)$ of the control group exhibited SSNHL $(p<0.001)$. The asthma group demonstrated a higher HR for SSNHL than the contro group (adjusted HR 1.23, 95\% $\mathrm{Cl} 1.11$ to $1.36, \mathrm{p}<0.001$ ). According to age and sex, the female subgroup showed elevated HRs for SSNHL in asthma patients. Both the non-smoker and current smoker groups demonstrated higher HRs for SSNHL in asthma patients than in controls. According to alcohol consumption or obesity, the $<1$ time a week alcohol consumption group and normal weight and severe obesity groups showed higher HRs for SSNHL in asthma patients than in the controls.

Conclusions Adult asthma patients had a higher risk of SSNHL than the control participants matched for demographic and socioeconomic factors.

\section{BACKGROUND}

Asthma is one of the most common airway disorders, and it is characterised by airway hyperresponsiveness and relapsing airway symptoms of wheezing and sputum. ${ }^{1}$ The prevalence of asthma was estimated to be approximately $4.2 \%$ (95\% CI $3.1 \%$ to $5.6 \%$ ) in the $\geq 20$-year-old population in East Asia. ${ }^{2}$ Asthma has several endotypes encompassing heterogeneous phenotypes with different
Strengths and limitations of this study

This study used a large, representative population cohort, which provided adequate statistical power.

- Comorbid conditions were adjusted for the analyses.

- However, because the study population of this study was Korean, the ethnic or regional differences could limit the generalisability of the present association between asthma and sudden sensorineural hearing loss.

- The duration and severity of asthma were heterogeneous, and pulmonary function test results were absent.

aetiologies. $^{3}{ }^{4}$ Genetic susceptibility, host factors and environmental factors were suggested to cause asthma. ${ }^{5}$ For host factors, in addition to allergic sensitisation, obesity was reported to increase the risk of asthma. ${ }^{6}$ For environmental factors, pollen, other aeroallergens and smoking could elevate the risk of asthma. ${ }^{7}$ These contributing factors result in airway inflammation and alter airway tone and reactivity, which evoke asthmatic symptoms. ${ }^{3}$ A growing number of researchers, not only those investigating airway pathophysiology, have proposed systemic or extrapulmonary manifestations of inflammation in asthma patients. ${ }^{8}$ For instance, asthma was suggested to be associated with cardiovascular and cerebrovascular disorders. ${ }^{9} 10$

Similarly, the pathophysiology of asthma, such as systemic inflammation and persistent hypoxia, could also implicate sensorineural hearing loss. The cochlea is an organ that is vulnerable to inflammation or ischaemic insertion, which could result in hearing loss. ${ }^{11}$ Owing to the blood supply requirements for the extensive collateral microvasculature, ${ }^{12}$ chronic hypoxia conditions can deteriorate cochlear function. ${ }^{11}$ In addition, inner ear inflammation and immune dysfunction can impact sensorineural hearing loss 


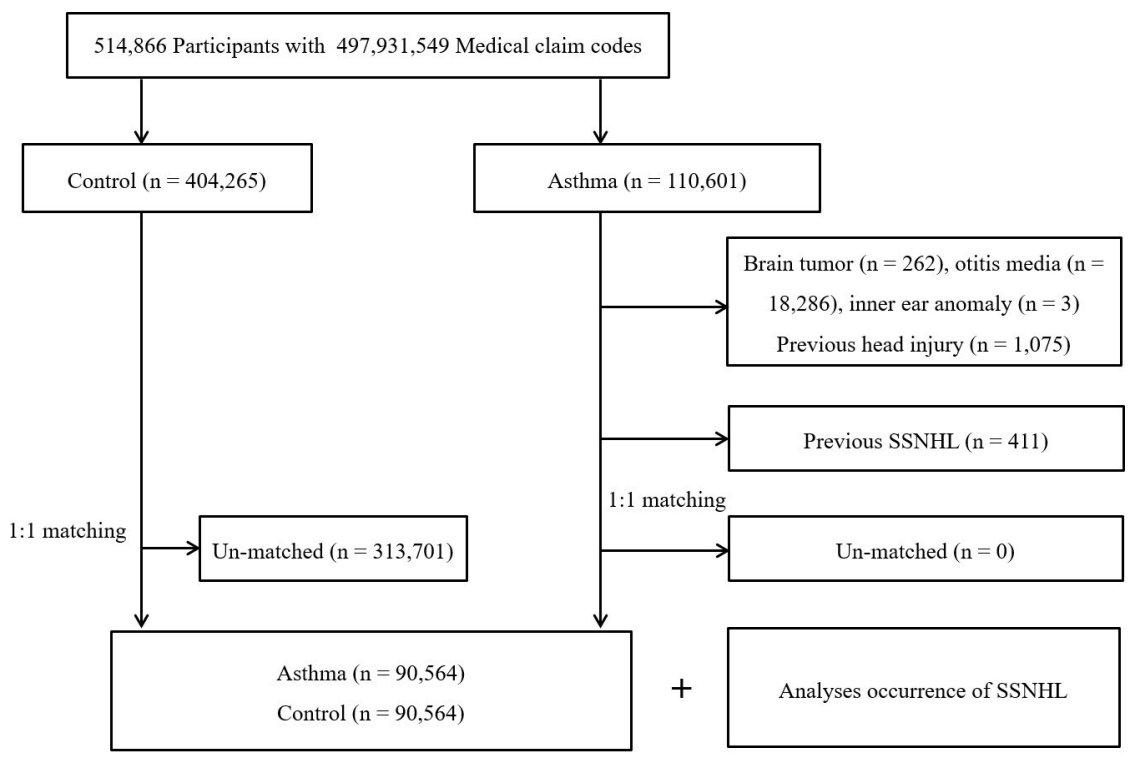

Figure 1 Schematic illustration of the participant selection process used in this study. Of a total of 514866 participants, 90 564 asthma patients were matched with 90564 control participants for age, sex, income and region of residence. SSNHL, sudden sensorineural hearing loss.

in patients with allergy. ${ }^{13}$ Among these sensorineural hearing loss cases, the sudden onset of sensorineural hearing loss across three continuous frequencies within 3 days for $30 \mathrm{~dB}$ HL is defined as sudden sensorineural hearing loss (SSNHL). ${ }^{14}$ The incidence of SSNHL was estimated to be approximately 5-20 per 100000 persons/ year worldwide. ${ }^{15}$ The pathophysiology of SSNHL is largely unknown and multifactorial. Approximately $71.0 \%-87.4 \%$ of SSNHL occurred without any organic causes. ${ }^{16-18}$ Less than $10 \%$ of SSNHL patients had brain tumours invading the internal auditory canal and causing inner ear anomaly. ${ }^{16}$ Inner ear pathophysiology related to inflammation, immune system dysfunction and

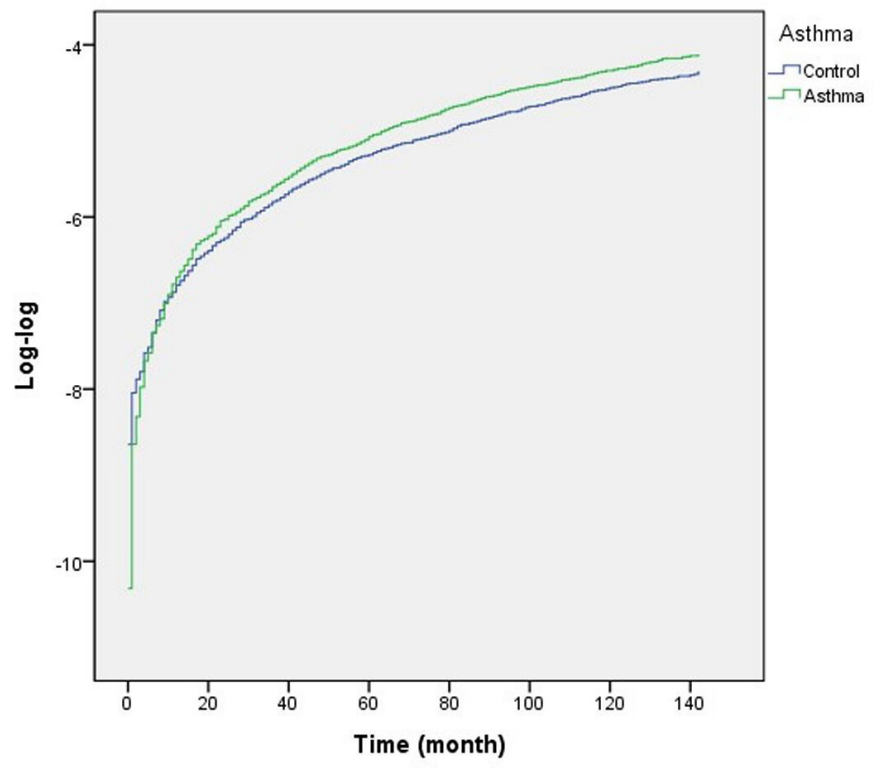

Figure 2 The log minus log plot for a proportional hazard assumption for sudden sensorineural hearing loss of asthma and control groups. vascular causes were suggested as contributing factors for SSNHL. ${ }^{1719}$ Based on a shared pathophysiological mechanism with cardiovascular and cerebrovascular disorders, a number of previous studies reported an increased risk of these diseases in SSNHL patients. ${ }^{20}$ Asthma also shares common pathophysiologies with SSNHL, namely, inflammation and immune system dysfunction. Therefore, there may be a relationship between asthma and SSNHL.

This study aimed to evaluate the risk of SSNHL in asthmatic adults. To the best of our knowledge, no prior study has investigated the association between SSNHL and asthma. When PubMed and EMBASE databases were searched for the keywords 'asthma' AND 'sudden hearing loss', no articles were retrieved until 1 July 2019. To minimise possible confounding effects, comorbidities and lifestyle factors associated with asthma were adjusted in this study. Moreover, SSNHL was confined to idiopathic cases by excluding cases of brain tumour, inner ear anomaly and head injury.

\section{METHODS}

Patient and public involvement statement

This national cohort study relied on data from the Korean National Health Insurance Service-Health Screening Cohort. A detailed description of these data was provided in our previously published study. ${ }^{21}$ This cohort based on the health claim code data and health screening database. This is a retrospective cohort study and participants did not intend to be collected or examined for study purpose.

\section{Participant selection}

Of the 514866 cases with 497931549 medical claim codes, we included participants who were diagnosed with asthma (ICD-10: J45) or status asthmaticus (J46) from 2002 through $2013(\mathrm{n}=110601)$ as reported in previous 
Table 1 General characteristics of participants

\begin{tabular}{|c|c|c|c|}
\hline \multirow[b]{2}{*}{ Characteristics } & \multicolumn{3}{|c|}{ Total participants } \\
\hline & $\begin{array}{l}\text { Asthma (n, } \\
\%)\end{array}$ & $\begin{array}{l}\text { Control } \\
\text { group (n, \%) }\end{array}$ & $P$ value \\
\hline Age (years old) & & & 1.000 \\
\hline $40-44$ & $5316(5.9)$ & $5316(5.9)$ & \\
\hline $45-49$ & 11747 (13.0) & $11747(13.0)$ & \\
\hline $50-54$ & $14272(15.8)$ & $14272(15.8)$ & \\
\hline $55-59$ & $14013(15.5)$ & $14013(15.5)$ & \\
\hline $60-64$ & $14084(15.6)$ & $14084(15.6)$ & \\
\hline $65-69$ & $13553(15.0)$ & $13553(15.0)$ & \\
\hline $70-74$ & 9982 (11.) & 9982 (11.) & \\
\hline $75-79$ & $5552(6.1)$ & $5552(6.1)$ & \\
\hline $80+$ & 2045 (2.3) & 2045 (2.3) & \\
\hline Sex & & & 1.000 \\
\hline Male & $40842(45.1)$ & $40842(45.1)$ & \\
\hline Female & $49722(54.9)$ & $49722(54.9)$ & \\
\hline Income & & & 1.000 \\
\hline 1 (lowest) & $15966(17.6)$ & $15966(17.6)$ & \\
\hline 2 & $13041(14.4)$ & 13041 (14.4) & \\
\hline 3 & $14266(15.8)$ & $14266(15.8)$ & \\
\hline 4 & $18676(20.6)$ & $18676(20.6)$ & \\
\hline 5 (highest) & 28615 (31.6) & $28615(31.6)$ & \\
\hline Region of residence & & & 1.000 \\
\hline Urban & $38170(42.1)$ & $38170(42.1)$ & \\
\hline Rural & 52394 (57.9) & $52394(57.9)$ & \\
\hline CCI score & & & $<0.001^{*}$ \\
\hline 0 & 89184 (98.5) & 87800 (96.9) & \\
\hline 1 & $122(0.1)$ & $538(0.6)$ & \\
\hline 2 & $180(0.2)$ & $474(0.5)$ & \\
\hline$\geq 3$ & $1078(1.2)$ & $1752(1.9)$ & \\
\hline Atopic dermatitis & $10622(11.7)$ & $7324(8.1)$ & $<0.001^{*}$ \\
\hline BMI & & & $<0.001^{*}$ \\
\hline <18.5 (underweight) & $2483(2.7)$ & $2456(2.7)$ & \\
\hline$\geq 18.5$ to $<23$ (normal) & 30140 (33.3) & 33446 (36.9) & \\
\hline$\geq 23$ to <25 (overweight) & $23826(26.3)$ & $24412(27.0)$ & \\
\hline$\geq 25$ to $<30$ (obese I) & 30706 (33.9) & $27687(30.6)$ & \\
\hline$\geq 30$ (obese II) & 3409 (3.8) & $2563(2.8)$ & \\
\hline Smoking & & & 0.551 \\
\hline Non-smoker or past smoker & $75610(83.5)$ & $75704(83.6)$ & \\
\hline Current smoker & $14954(16.5)$ & $14860(16.4)$ & \\
\hline Drinking alcohol & & & $<0.001^{*}$ \\
\hline$<1$ time a week & 71773 (79.3) & $70381(77.7)$ & \\
\hline$\geq 1$ time a week & $18791(20.7)$ & $20183(22.3)$ & \\
\hline SSNHL & $877(1.0)$ & $706(0.8)$ & $<0.001^{*}$ \\
\hline
\end{tabular}

${ }^{*} \mathrm{X}^{2}$ test. Significance at $\mathrm{p}<0.05$.

$\mathrm{BMI}$, body mass index; CCl, Charlson Comorbidity Index; SSNHL, sudden sensory neural hearing loss.

studies. ${ }^{22}{ }^{23}$ We excluded participants in both asthma and control groups who had a history of brain tumour (C70C72), otitis media or a history of a head injury. Among
Table 2 Crude and adjusted HRs $(95 \% \mathrm{Cl})$ of asthma for SSNHL according to age and sex

\begin{tabular}{|c|c|c|c|c|}
\hline \multirow[b]{2}{*}{ Characteristics } & \multicolumn{4}{|c|}{ HRs for SSNHL } \\
\hline & Crude $^{*}$ & $P$ value & Adjusted $^{*} \dagger$ & $P$ value \\
\hline \multicolumn{5}{|c|}{ Total participants $(n=181128)$} \\
\hline Asthma & $\begin{array}{l}1.24 \text { (1.12 to } \\
1.37)\end{array}$ & $<0.001 \ddagger$ & $\begin{array}{l}1.23 \text { (1.11 to } \\
1.36)\end{array}$ & $<0.001 \ddagger$ \\
\hline Control & 1.00 & & 1.00 & \\
\hline \multicolumn{5}{|c|}{ Age $<60$ years old, men $(n=40166)$} \\
\hline Asthma & $\begin{array}{l}1.27 \text { (1.03 to } \\
1.56)\end{array}$ & $0.024 \ddagger$ & $\begin{array}{l}1.22 \text { (0.99 to } \\
1.51)\end{array}$ & 0.058 \\
\hline Control & 1.00 & & 1.00 & \\
\hline \multicolumn{5}{|c|}{ Age $<60$ years old, women $(n=50530)$} \\
\hline Asthma & $\begin{array}{l}1.28 \text { (1.08 to } \\
1.53)\end{array}$ & $0.006 \ddagger$ & $\begin{array}{l}1.29 \text { (1.08 to } \\
1.54)\end{array}$ & $0.005 \ddagger$ \\
\hline Control & 1.00 & & 1.00 & \\
\hline \multicolumn{5}{|c|}{ Age $\geq 60$ years old, men $(n=41518)$} \\
\hline Asthma & $\begin{array}{l}1.15 \text { (0.93 to } \\
1.43)\end{array}$ & 0.187 & $\begin{array}{l}1.15 \text { (0.93 to } \\
1.43)\end{array}$ & 0.195 \\
\hline Control & 1.00 & & 1.00 & \\
\hline \multicolumn{5}{|c|}{ Age $\geq 60$ years old, women $(n=48914)$} \\
\hline Asthma & $\begin{array}{l}1.24 \text { (1.01 to } \\
1.52)\end{array}$ & $0.039 \ddagger$ & $\begin{array}{l}1.24 \text { (1.01 to } \\
1.52)\end{array}$ & $0.038 \ddagger$ \\
\hline Control & 1.00 & & 1.00 & \\
\hline
\end{tabular}

*Stratified model for age, sex, income and region of residence. †Adjusted model for Charlson Comorbidity Index, obesity (BMI), smoking, alcohol intake, atopic dermatitis histories.

$\ddagger$ Cox-proportional hazard regression model, significance at $p<0.05$. $\mathrm{BMI}$, body mass index; SSNHL, sudden sensorineural hearing loss.

them, we excluded participants who had a previous history of SSNHL. The numbers of excluded participants among asthma patients were 262 for the history of brain tumour, 18286 for the history of otitis media, 1075 for the previous history of a head injury and 411 for a history of SSNHL. The participants were followed through 31 December 2013. SSNHL was diagnosed according to ICD-10 codes (H912), the audiometry exam (claim codes: E6931-E6937, F6341-F6348) and steroid treatment. ${ }^{24}$

The asthma group was matched 1:1 with participants (control group) who were not diagnosed with asthma from 2002 to 2013. From the total population $(n=404$ 265), the control group was selected. Among them, we excluded participants who had a history of brain tumour $(n=844)$, otitis media $(n=42700)$ or inner ear anomaly $(n=18)$. Matching was performed for age, sex, income and region of residence.

To prevent selection bias when enrolling the matched participants, the control participants were sorted using a random number order and then selected from top to bottom. We set the index date as the date of the diagnosis of asthma. It was assumed that the matched control participants were involved at the same time as the asthma participants (index date). Therefore, the control patients who died before the index date or who had a history of SSNHL before the index date were replaced. Participants with a 


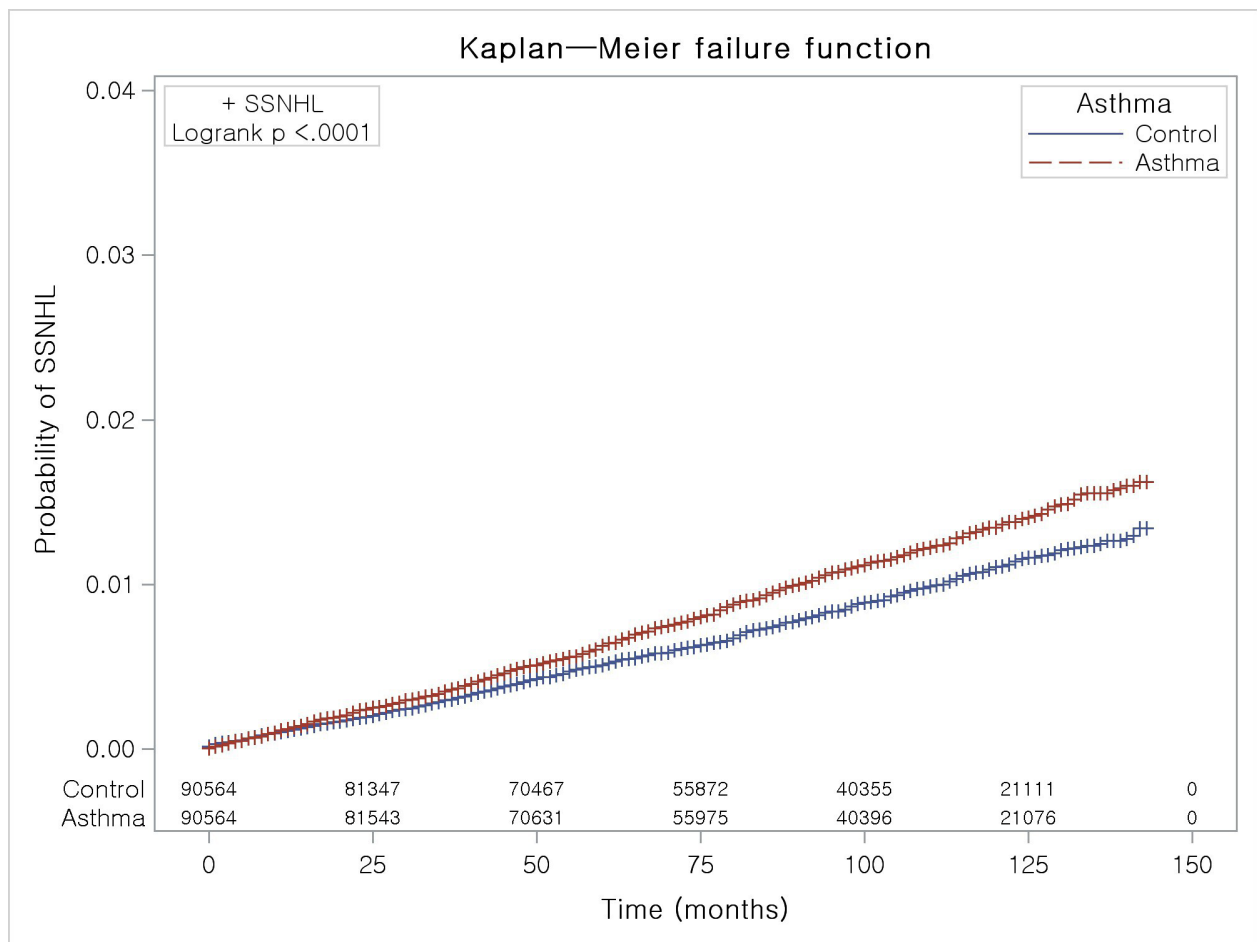

Figure 3 Kaplan-Meier survival curve of asthma for sudden sensorineural hearing loss (SSNHL) (a 1 - survival function curve).

history of SSNHL before the index date were excluded from the asthma group $(\mathrm{n}=411)$. All asthma patients were matched with a control participant. The mean follow-up time from the index date to the last follow-up date (31 December 2013) or the date of death was similar in both the asthma group (87.28 months, $\mathrm{SD}=40.56)$ and control group (87.02 months, $\mathrm{SD}=40.78)$. Finally, 1:1 matching resulted in the inclusion of 90564 asthma patients and 90 564 control participants (figure 1).

\section{Variables}

Age, sex, income and region of residence were defined as reported previous studies. ${ }^{23}{ }^{25}$ Brain tumour histories were included according to ICD-10 codes (C70-C72). Inner ear anomaly histories were included according to ICD-10 codes of Q16. Head injury histories were included according to ICD-10 codes of S00-S09 with claim codes of brain CT (HA 401 HA 472).

For tobacco smoking, patients were categorised according to their current smoking status (non-smoker and former/current smoker) ${ }^{26}$ For alcohol consumption, patients were categorised according to frequency $(<1$ time a week and $\geq 1$ time a week). ${ }^{26}$ For obesity, patients were categorised as having a body mass index (BMI, kg/ $\mathrm{m}^{2}$ ) of $<18.5$ (underweight), $\geq 18.5$ to $<23$ (normal), $\geq 23$ to $<25$ (overweight), $\geq 25$ to $<30$ (obese I) and $\geq 30$ (obese II) following WPRO 2000. ${ }^{27}$ The Charlson Comorbidity Index (CCI) was used for 16 comorbidities, excluding pulmonary disease as a continuous variable $(0$ (no comorbidity) through 28 (multiple comorbidities))..$^{28}$ Atopic dermatitis was defined according to the ICD-10 code of L20.

\section{Statistical analyses}

$\chi^{2}$ tests were used to compare the general characteristics between the asthma and control groups.

Stratified Cox proportional hazard models were used to assess HRs for SSNHL with respect to asthma. In this analysis, crude (simple) and adjusted models (for CCI score, obesity, smoking, alcohol consumption and atopic dermatitis histories) were used, and 95\% CIs were calculated. In these analyses, age, sex, income and region of residence were stratified. Kaplan-Meier analysis and the log rank test were used. The proportional hazard assumption was tested using log minus log plot (figure 2).

For subgroup analyses, we divided the participants by age and sex $(<60$ years old and $\geq 60$ years old; male and female) to confirm that these relations were reliable according to age and sex. In another subgroup analysis, we analysed HRs according to smoking status, alcohol consumption status and obesity because we believe that these lifestyle factors could influence the occurrence of SSNHL.

Two-tailed analyses were conducted, and $p$ values less than 0.05 were considered to indicate significance. The results were statistically analysed using SPSS V.22.0 (IBM) and SAS V.9.4 (SAS Institute).

\section{RESULTS}

The duration from the index date to SSNHL ( $\geq 1$ time) was 86.66 months $(\mathrm{SD}=40.88)$ in the asthma group and 86.82 months $(\mathrm{SD}=40.67)$ in the control group. The rates of SSNHL were higher in the asthma group $(1.0 \%(877 / 90$ $564)$ ) than in the control group (0.8\% (706/90 564), 
Table 3 Crude and adjusted HRs $(95 \% \mathrm{Cl})$ of asthma for SSNHL according to smoking, drinking alcohol and obesity

\begin{tabular}{|c|c|c|c|c|}
\hline \multirow[b]{2}{*}{ Characteristics } & \multicolumn{4}{|c|}{ HRs for SSNHL } \\
\hline & Crude & $P$ value & Adjusted* & $P$ value \\
\hline \multicolumn{5}{|c|}{ Non or past smoker $(n=151314)$} \\
\hline Asthma & $\begin{array}{l}1.21 \text { (1.09 to } \\
1.35)\end{array}$ & $<0.001 \dagger$ & $\begin{array}{l}1.20(1.08- \\
1.33)\end{array}$ & $0.001 \dagger$ \\
\hline Control & 1.00 & & 1.00 & \\
\hline \multicolumn{5}{|c|}{ Current smoker ( $n=29814)$} \\
\hline Asthma & $\begin{array}{l}1.47 \text { (1.11 to } \\
1.95)\end{array}$ & $0.007 \dagger$ & $\begin{array}{l}1.45(1.09- \\
1.93)\end{array}$ & $0.010 \dagger$ \\
\hline Control & 1.00 & & 1.00 & \\
\hline \multicolumn{5}{|c|}{ Drinking alcohol $<1$ time a week $(n=142154)$} \\
\hline Asthma & $\begin{array}{l}1.24 \text { (1.11 to } \\
1.39)\end{array}$ & $<0.001 \dagger$ & $\begin{array}{l}1.24(1.11- \\
1.38)\end{array}$ & $<0.001 \dagger$ \\
\hline Control & 1.00 & & 1.00 & \\
\hline
\end{tabular}

Drinking alcohol $\geq 1$ time a week $(n=38974)$

\begin{tabular}{|c|c|c|c|c|}
\hline Asthma & $\begin{array}{l}1.21 \text { ( } 0.97 \text { to } \\
1.52)\end{array}$ & 0.099 & $\begin{array}{l}1.19 \text { (0.95- } \\
1.49)\end{array}$ & 0.140 \\
\hline Control & 1.00 & & 1.00 & \\
\hline \multicolumn{5}{|c|}{ Under weight $(\mathrm{BMI}<18.5, \mathrm{n}=4939)$} \\
\hline Asthma & $\begin{array}{l}0.60(0.29 \text { to } \\
1.25)\end{array}$ & 0.176 & $\begin{array}{l}0.59(0.28- \\
1.23)\end{array}$ & 0.157 \\
\hline Control & 1.00 & & 1.00 & \\
\hline \multicolumn{5}{|c|}{ Normal weight (BMI $\geq 18.5$ to $<23, n=63586)$} \\
\hline Asthma & $\begin{array}{l}1.25 \text { (1.05 to } \\
1.48)\end{array}$ & $0.012 \dagger$ & $\begin{array}{l}1.24(1.05- \\
1.48)\end{array}$ & $0.013 \dagger$ \\
\hline Control & 1.00 & & 1.00 & \\
\hline \multicolumn{5}{|c|}{ Overweight (BMI $\geq 23$ to $<25, \mathrm{n}=48238$ ) } \\
\hline Asthma & $\begin{array}{l}1.20(1.00 \text { to } \\
1.45)\end{array}$ & 0.053 & $\begin{array}{l}1.20(0.99- \\
1.44)\end{array}$ & 0.063 \\
\hline Control & 1.00 & & 1.00 & \\
\hline \multicolumn{5}{|c|}{ Obese I (BMI $\geq 25$ to $<30, n=58$ 393) } \\
\hline Asthma & $\begin{array}{l}1.37 \text { (1.15 to } \\
1.62)\end{array}$ & $<0.001 \dagger$ & $\begin{array}{l}1.35(1.13- \\
1.60)\end{array}$ & $0.001 \dagger$ \\
\hline Control & 1.00 & & 1.00 & \\
\hline \multicolumn{5}{|c|}{ Obese II (BMI $\geq 30, n=5972)$} \\
\hline Asthma & $\begin{array}{l}0.73 \text { (0.39 to } \\
1.36)\end{array}$ & 0.321 & $\begin{array}{l}0.73(0.39- \\
1.36)\end{array}$ & 0.325 \\
\hline Control & 1.00 & & 1.00 & \\
\hline
\end{tabular}

*Adjusted model for age, sex, income, region of residence, Charlson Comorbidity Index, obesity (BMI), smoking, alcohol intake, atopic dermatitis histories.

†Non-stratified Cox-proportional hazard regression model, significance at $p<0.05$.

BMI, body mass index; SSNHL, sudden sensorineural hearing loss.

$\mathrm{p}<0.001$, table 1$)$. No differences in the general characteristics of the participants (age, sex, income and region of residence) were found due to the matching procedure $(\mathrm{p}=1.000)$. However, the CCI score was different between the asthma and control groups $(\mathrm{p}<0.001)$, the rate of atopic dermatitis was higher in the asthma group than in the control group $(\mathrm{p}<0.001)$, and the distributions of obesity and alcohol consumption were different between the asthma and control groups $(\mathrm{p}<0.001)$.

The adjusted HR of SSNHL was 1.23 (95\% CI 1.11 to $1.36)$ in the asthma group ( $p<0.001$, table 2$)$. KaplanMeier analysis showed consistent results (figure 3). In subgroup analyses according to age and sex, the adjusted HRs were 1.29 (95\% CI 1.08 to 1.54 ) in <60-year-old women and 1.24 (95\% CI 1.01 to 1.52 ) in $\geq 60$-year-old women.

According to smoking status, both the non-smoker and former/current smoker subgroups showed elevated HRs for SSNHL in the asthma group compared with the control group (table 3). The adjusted HRs were 1.20 (95\% CI 1.08 to 1.33 ) in nonsmokers and former smokers and 1.45 (95\% CI 1.09 to 1.93 ) in current smokers. According to alcohol consumption, the alcohol consumption subgroup demonstrated increased HR for SSNHL in the asthma group (adjusted HR 1.24, 95\% CI 1.11 to 1.38 ). For obesity, the normal weight group and obese I group demonstrated increased HR for SSNHL in the asthma group (adjusted HR 1.24, 95\% CI 1.05 to 1.48 of normal weight and adjusted HR 1.35, 95\% CI 1.13 to 1.60 for obese I).

\section{DISCUSSION}

The risk of developing SSNHL was 1.23 times higher in adult asthma patients than in the control group matched for demographic and socioeconomic factors. This association was independent of comorbidities such as allergies and lifestyle factors of obesity, alcohol consumption and smoking. The metabolic syndrome components, including obesity and medical histories using CCI scores (diabetes) were adjusted because these factors have been suggested as predictors of SSNHL and asthma. ${ }^{29} 30$ According to sex, the female subgroup demonstrated a higher risk of SSNHL in the asthma patients than in the matched controls. The novelty of this study is that it delineates the risk of SSNHL in asthma patients. Clinicians need to be aware of the potential risk of SSNHL when managing asthmatic patients. A few plausible mechanisms could mediate this risk.

The allergic response in asthma patients could impact the elevated risk of SSNHL. Previous studies have demonstrated the etiologic role of allergy for SSNHL. ${ }^{13} 3132$ A few case reports have described SSNHL following IgEmediated inflammatory responses. ${ }^{31}{ }^{32}$ In a cross-sectional study, patients in the adult asthma group showed higher serum IgE levels than the age-matched control group $(\mathrm{p}<0.001) .{ }^{13}$ An allergy history was reported in $61.9 \%$ of asthma patients, which was higher than that reported in the control group $(21.8 \%) .{ }^{13}$ The histamine and the degranulated mediators of mast cells could induce the vasodilation of inner ear vessels, impeding lymphatic circulation in the inner ear. ${ }^{33}$ Circulating immune complexes could also occlude the strial capillaries and induce cochlear ischemia. ${ }^{34}$ In addition, an allergic response could evoke inflammatory cascades via lymphocytes and macrophages 
of the inner ear, leading to inflammation and dysfunction of the inner ear. ${ }^{35}$

In addition to an allergic response, other inflammatory mechanisms in asthma patients could induce inner ear inflammation and result in SSNHL. Only approximately $50 \%$ of asthma patients had Th2-high responses, while others had Th2-low cytokine profiles with neutrophilia and systemic inflammation. ${ }^{36}$ This systemic inflammation might be linked to extrapulmonary disorders, including cardiovascular and metabolic diseases. ${ }^{6}{ }^{10}$ For instance, asthma patients with obesity demonstrated high levels of serum $\mathrm{C}$ reactive protein, representing a systemic inflammatory response. ${ }^{37}$ Similarly, these inflammatory conditions could influence inner ear inflammation and SSNHL.

The recurrent hypoxic conditions in asthma patients could act as an insult to the cochlear blood supply and cause SSNHL. Several previous studies have reported auditory dysfunction in patients with chronic lung disease. ${ }^{38-40}$ The transient evoked otoacoustic emission, which primarily originates from outer hair cells, was found to be decreased in children with chronic lung disease compared with age-matched and sex-matched controls. ${ }^{38}$ These results implied that outer hair cell functions were impaired following chronic exposure to hypoxia. Another case-control study demonstrated elevated hearing thresholds in pure tone audiometry and delayed interpeak latencies in the auditory brainstem response (ABR) in chronic obstructive lung disease patients. ${ }^{39}$ Because the ABR records the evoked auditory response from multiple auditory brainstem nuclei, the abnormality in ABR implied the involvement of retrocochlear dysfunction as well as cochlear OHC dysfunction following hypoxic conditions. Because asthma is a pulmonary disorder with reversible airway obstruction, the impact of hypoxia might be less than that of other chronic lung diseases. However, the accumulated effects of recurrent hypoxic attack could result in cochlear dysfunction. Indeed, a previous study reported elevated hearing thresholds at high frequencies $(10-20 \mathrm{kHz})$ in asthma patients. ${ }^{40}$ The high frequencies are tonotopically allocated to the basal turn of the cochlea, which is susceptible to hypoxic injuries. ${ }^{41}$

According to lifestyle factors, the participants without lifestyle risk factors, less alcohol consumption and normal BMI showed consistent results for the relationship between asthma and SSNHL in this study. The non-significant association of asthma with SSNHL in participants with life style risk factors can be explained by the comorbid conditions susceptible to both asthma and SSNHL. Because smoking and alcohol consumption were supposed to increase the risk of SSNHL, the contribution of asthma on the development of SSNHL could not be as high as to reach the statistical significance. ${ }^{42-44}$ The participants in obese I (BMI $\geq 25$ to $<30 \mathrm{~kg} / \mathrm{m}^{2}$ ) also showed positive association of asthma with SSNHL in this study. In addition, the HR of obese I participants was higher than that of normal weight participants. The distinctive features of obese asthma could induce the elevated risk of SSNHL in this population. ${ }^{45}$ The obese asthmatic patients were reported to suffer more symptoms, frequent and severe exacerbations, and refractory to some asthma medications. ${ }^{45}$

\section{Limitations}

This study used a large, representative population cohort, which provided adequate statistical power. The large number of participants in the cohorts permitted the unbiased selection of control groups matched for both demographic and socioeconomic factors. In addition, comorbid conditions were adjusted using CCI. Lifestyle factors such as obesity, alcohol consumption and smoking were also adjusted and analysed using subgroups. The diagnoses of asthma and SSNHL were based on objective criteria according to ICD-10 codes and medication histories. However, this study had a few limitations, which should be noted. Although many comorbid conditions were considered, the metabolic syndrome components could not be fully evaluated in the current study. Because the study population of this study was Korean, the ethnic or regional differences could be limit the generalisability of the present association between asthma and SSNHL. In addition, the duration and severity of asthma were heterogeneous, and pulmonary function test results were absent. Similarly, the degree and prognosis of hearing loss in SSNHL were not considered. Further studies are warrant to clarify the specific types of asthma which pose higher risk of SSNHL and the characteristics and prognosis of SSNHL in asthmatic patients.

\section{Conclusions}

Asthma was associated with an increased risk of SSNHL in the adult asthma population compared with controls matched for demographic and socioeconomic factors. The potential contribution of asthma on the development of SSNHL will need to be considered when treating both asthma and SSNHL patients.

Acknowledgements This work was supported in part by a research grant (NRF- 2020R1A2C4002594 and NRF-2018-R1D1A1A02085328) from the National Research Foundation (NRF) of Korea.

Contributors HGC designed the study; CM and CHL analysed the data; SYK and $\mathrm{HGC}$ drafted and revised the paper; and HGC drew the figures. All authors have read and agreed to the published version of the manuscript.

Funding This work was supported in part by a research grant (NRF-2018R1D1A1A02085328 and 2020R1A2C4002594) from the National Research Foundation (NRF) of Korea.

Disclaimer The funders had no role in study design, data collection and analysis, decision to publish, or preparation of the manuscript.

Competing interests None declared.

Patient and public involvement Patients and/or the public were not involved in the design, or conduct, or reporting, or dissemination plans of this research.

\section{Patient consent for publication Not applicable.}

Ethics approval The Ethics Committee of Hallym University (2017-1102) approved the use of these data. Written informed consent was waived by the institutional review board.

Provenance and peer review Not commissioned; externally peer reviewed. 
Data availability statement Data may be obtained from a third party and are not publicly available. Release of the data by the researcher is illegal. All data are available from the National Health Insurance Sharing Service (NHISS) database (https://nhiss.nhis.or.kr/).The NHISS allows all of these data to be used by any researcher who promises to follow the research ethics guidelines, with some associated costs. If one wants to access the data of this article, one can download them from the website after promising to adhere to the research ethics requirements.

Open access This is an open access article distributed in accordance with the Creative Commons Attribution Non Commercial (CC BY-NC 4.0) license, which permits others to distribute, remix, adapt, build upon this work non-commercially, and license their derivative works on different terms, provided the original work is properly cited, appropriate credit is given, any changes made indicated, and the use is non-commercial. See: http://creativecommons.org/licenses/by-nc/4.0/.

\section{ORCID iDs}

Hyo Geun Choi http://orcid.org/0000-0003-1655-9549

So Young Kim http://orcid.org/0000-0002-7361-4930

\section{REFERENCES}

1 Asher MI, Montefort S, Björkstén B, et al. Worldwide time trends in the prevalence of symptoms of asthma, allergic rhinoconjunctivitis, and eczema in childhood: ISAAC phases one and three repeat multicountry cross-sectional surveys. Lancet 2006;368:733-43.

2 Huang K, Yang T, Xu J, et al. Prevalence, risk factors, and management of asthma in China: a national cross-sectional study. Lancet 2019;394:407-18.

3 Pavord ID, Beasley R, Agusti A, et al. After asthma: redefining airways diseases. Lancet 2018;391:350-400.

4 McDowell PJ, Heaney LG. Different endotypes and phenotypes drive the heterogeneity in severe asthma. Allergy 2020;75:302-10.

5 Dharmage SC, Perret JL, Custovic A. Epidemiology of asthma in children and adults. Front Pediatr 2019;7:246.

6 Gomez-Llorente $\mathrm{M}^{\mathrm{a}}$, Romero R, Chueca N, et al. Obesity and asthma: a missing link. Int J Mol Sci 2017;18:1490.

$7 \mathrm{Kim}$ SY, Sim S, Choi HG. Active and passive smoking impacts on asthma with quantitative and temporal relations: a Korean community health survey. Sci Rep 2018;8:8614.

8 Rastogi D, Holguin F. Metabolic dysregulation, systemic inflammation, and pediatric obesity-related asthma. Ann Am Thorac Soc 2017;14:S363-7.

9 Wen L-Y, Ni H, Li K-S, et al. Asthma and risk of stroke: a systematic review and meta-analysis. J Stroke Cerebrovasc Dis 2016;25:497-503.

10 Hung MJ, Mao CT, Hung MY. Impact of asthma on the development of coronary vasospastic angina: a population-based cohort study. Medicine 2015;94:e1880.

11 Bayat A, Saki N, Nikakhlagh S, et al. Is COPD associated with alterations in hearing? A systematic review and meta-analysis. Int $J$ Chron Obstruct Pulmon Dis 2019;14:149-62.

12 Penha R, O'Neill MA, Goyri O'Neill J, et al. Ultrastructural aspects of the microvasculature of the cochlea: the internal spiral network. Otolaryngol Head Neck Surg 1999;120:725-9.

13 Keleș E, Sapmaz E, Gödekmerdan A. The role of allergy in the etiopathogenesis of idiopathic sudden sensorineural hearing loss. Eur Arch Otorhinolaryngol 2013;270:1795-801.

14 Rauch SD. Clinical practice. idiopathic sudden sensorineural hearing loss. N Engl J Med 2008;359:833-40.

15 Byl FM. Sudden hearing loss: eight years' experience and suggested prognostic table. Laryngoscope 1984;94:647-61.

16 Cho J, Cheon H, Park JH, et al. Sudden sensorineural hearing loss associated with inner ear lesions detected by magnetic resonance imaging. PLoS One 2017;12:e0186038.

17 Chau JK, Lin JRJ, Atashband S, et al. Systematic review of the evidence for the etiology of adult sudden sensorineural hearing loss. Laryngoscope 2010;34

18 Park KV, Oh KH, Jeong YJ, et al. Machine learning models for predicting hearing prognosis in unilateral idiopathic sudden sensorineural hearing loss. Clin Exp Otorhinolaryngol 2020;13:148-56.

19 Kuzucu İhsan, Çandar T, Baklacı D, et al. A prognostic marker in idiopathic sudden sensorineural hearing loss: serum calprotectin. Clin Exp Otorhinolaryngol 2020;13:36-40.
20 Kitoh R, Nishio S-ya, Ogawa K, et al. Nationwide epidemiological survey of idiopathic sudden sensorineural hearing loss in Japan. Acta Otolaryngol 2017;137:S8-16.

21 Kim SY, Min C, Oh DJ, et al. Tobacco smoking and alcohol consumption are related to benign parotid tumor: a nested casecontrol study using a national health screening cohort. Clin Exp Otorhinolaryngol 2019;12:412-9.

$22 \mathrm{Kim} \mathrm{S}$, Kim J, Kim K, et al. Healthcare use and prescription patterns associated with adult asthma in Korea: analysis of the $\mathrm{NHI}$ claims database. Allergy 2013;68:1435-42.

23 Choi HG, Kim J-H, Park J-Y, et al. Association Between Asthma and Depression: A National Cohort Study. J Allergy Clin Immunol 2019;7:1239-45.

24 Choi HG, Min C, Kim SY. Air pollution increases the risk of SSNHL: a nested case-control study using meteorological data and national sample cohort data. Sci Rep 2019;9:8270.

25 Choi HG, Lee JK, Kong IG, et al. Osteoporosis increases the risk of benign paroxysmal positional vertigo: a nested case-control study using a national sample cohort. Eur Arch Otorhinolaryngol 2019;276:335-42.

26 Kim SY, Min C, Yoo DM, et al. Hearing impairment increases economic inequality. Clin Exp Otorhinolaryngol 2021;14:278-86.

27 WHO/IASO/IOTR. The Asia-Pacific Perespective: redefining obesity and its treatment. Health Communications, Australia Pty Ltd, 2000.

28 Quan $\mathrm{H}$, Li B, Couris CM, et al. Updating and validating the Charlson comorbidity index and score for risk adjustment in hospital discharge abstracts using data from 6 countries. Am J Epidemiol 2011;173:676-82.

29 Lim M-S, Lee CH, Sim S, et al. Physical activity, sedentary habits, sleep, and obesity are associated with asthma, allergic rhinitis, and atopic dermatitis in Korean adolescents. Yonsei Med $\mathrm{J}$ 2017;58:1040-6.

30 Lee JS, Kim DH, Lee HJ, et al. Lipid profiles and obesity as potential risk factors of sudden sensorineural hearing loss. PLoS One 2015;10:e0122496.

31 Hall AC, Leong AC, Jiang D, et al. Sudden bilateral sensorineural hearing loss associated with urticarial vasculitis. J Laryngol Otol 2013;127:708-11.

32 Düzenli U, Bozan N, Ayral A, et al. A honey bee can threat ear: sudden sensorineural hearing loss. Am J Emerg Med 2017;35:1788. e1-8.

33 Baldwin RL, Formby C. Changes in caloric nystagmus induced by vasodilating drugs. Laryngoscope 1986;96:420-9.

34 Brookes GB. Circulating immune complexes in Meniere's disease. Arch Otolaryngol Head Neck Surg 1986;112:536-40.

35 Kämpfe Nordström C, Danckwardt-Lillieström N, Laurell G, et al. The human endolymphatic sac and inner ear immunity: macrophage interaction and molecular expression. Front Immunol 2018;9:3181.

36 Lambrecht BN, Hammad H, Fahy JV. The cytokines of asthma. Immunity 2019;50:975-91.

37 Cordova-Rivera L, Gibson PG, Gardiner PA, et al. Extrapulmonary associations of health status in severe asthma and bronchiectasis: comorbidities and functional outcomes. Respir Med 2019;154:93-101.

38 Ibrahim HM, Kamel TB, Abdel-Salam NMS, et al. Study of auditory function in children with chronic lung diseases. Int $J$ Pediatr Otorhinolaryngol 2011;75:39-42.

39 El-Kady MA, Durrant JD, Tawfik S, et al. Study of auditory function in patients with chronic obstructive pulmonary diseases. Hear Res 2006;212:109-16.

40 Kilic T, Karatas E, Toplu Y. Evaluation of auditory functions in patients with asthma. Eur Rev Med Pharmacol Sci 2014;18:2615-20.

41 Hwang J-H, Hsu C-J, Yu W-H, et al. Diet-induced obesity exacerbates auditory degeneration via hypoxia, inflammation, and apoptosis signaling pathways in CD/1 mice. PLoS One 2013;8:e60730.

42 Matschke RG. Smoking habits in patients with sudden hearing loss. Preliminary results. Acta Otolaryngol Suppl 1990;476:69-73.

43 Umesawa M, Kobashi G, Kitoh R, et al. Relationships among drinking and smoking habits, history of diseases, body mass index and idiopathic sudden sensorineural hearing loss in Japanese patients. Acta Otolaryngol 2017;137:S17-23.

44 Antonopoulos S, Balatsouras DG, Kanakaki S, et al. Bilateral sudden sensorineural hearing loss caused by alcohol abuse and heroin sniffing. Auris Nasus Larynx 2012;39:305-9.

45 Peters U, Dixon AE, Forno E. Obesity and asthma. J Allergy Clin Immunol 2018;141:1169-79. 